\title{
The Development of Children when a Parent Experiences Mental Disorder: Stigma, Communication, and Humanization
}

\author{
Stephen P. Hinshaw \\ University of California, Berkeley, CA, USA; University of California, San Francisco, CA, USA
}

I've spent my career engaged in the discipline of developmental psychopathology, primarily examining biological, familial, peer-related, and wider social influences on children's self-regulation and impulse control. In recent decades I've been far more explicit about my motivations for this passion and for my continuing mission to (a) reduce stigma and (b) promote integration of psychobiological with psychosocial/cultural influences regarding the roots of mental and developmental disorders. Specifically, I have published narrative accounts of the serious mental disorder, interlaced with high achievement, permeating my family - particularly my father, with his lifelong, misdiagnosed, and quite severe bipolar disorder [see Hinshaw, 2017a, for a book-length account].

In the relatively short space allocated to the Editor's Corner, I discuss what is known about the issue of the development of children who grow up in homes in which parental mental illness plays a prominent role [see Beardslee, Gladstone, \& O'Connor, 2011; Goodman \& Gotlib, 1999]. In so doing I illuminate the intersecting roles of genetic vulnerability, aberrant family communication (especially the absence of relevant communication), and the promotion of resilient functioning in offspring.

To contextualize this issue, I provide a brief account of my family background before conveying a headline-level review of the ongoing stigmatization of mental illness. Indeed, despite what appears to be greater openness in society about the entire topic of mental disorder - and despite far greater public knowledge of mental health over the past half-century - stigma and social distance are expanding rather than receding [e.g., Pescosolido et al., 2010]. Next, I cover the mechanisms by which mood disorders, in particular, may be transmitted to offspring and discuss extremely promising efforts to enhance family communication and thereby prevent children from internalizing the attendant family conflict. A crucial convergence of genetically transmitted and psychosocially mediated risk is evident in this work. In the end, I contend that synthesizing current developmental science with a stance of humanization will allow investigators and practitioners to put a dent in the underlying shame, silence,

\section{KARGER}

E-Mail karger@karger.com www.karger.com/hde
(C) 2018 S. Karger AG, Basel 
and denigration related to family mental illness, at the same time promoting the kinds of evidence-based interventions that can open up family communication and reduce the risk for intergenerational transmission, especially with respect to mood disorders.

\section{Family Motivation}

I grew up in a seemingly idyllic Midwestern family - warm, academic, and from outside appearances stable. Yet my philosopher father periodically disappeared, without warning or explanation, for months at a time, even a full year during his longest absence. My younger sister and I had no idea that he was involuntarily placed in brutal mental facilities for what was believed to be chronic schizophrenia. All this had begun when he was 16, during the mid-1930s, when he came to believe that he could save the world from the oncoming Nazi threat with his newfound (and obviously delusional) conviction that he could fly. Throughout his life, episodes of utter madness recurred, intermixed with his brilliance as a philosophy student and then professor and his responsiveness as a father (when he was around). When he mysteriously reemerged into our home after yet another absence, he seemed perfectly normal, adding to the mystery and the terror.

He once asked his lead psychiatrist what to tell my sister and me about his periodic, lengthy absences: the response was that he and my mother must never mention the topic, lest their children be permanently destroyed. The consequences of such professionally enforced silence comprise the subject matter of Hinshaw [2017a], entitled Another Kind of Madness: A Journey through the Stigma and Hope of Mental Illness.

Once I'd left for college, my father finally divulged the truth during my freshman-year spring break, then spanning a series of conversations over the next quarter century, until he passed away. Upon hearing his revelations, I quickly became engaged in clinical psychology and developmental psychopathology, working to help children and teens who were "lost" and to take on wider issues related to the etiology and treatment of mental illness. Yet for a number of years I was terrified that I'd be next in line for psychosis and mental hospitalization. Until I opened up sufficiently to receive support, the fear was palpable. Along with many of my current research and advocacy efforts, this book comprises an attempt to convey a deeply human story of shame, redemption, and hope, encompassing my career-long aim to bring evidence-based intervention and prevention models to the many families in need of such efforts.

\section{Stigma}

Stigma literally signifies a brand or mark, burned into the skin of members of devalued groups, to indicate visibly their low social status and disgrace [Hinshaw, 2007]. Today, most stigma is inferred from outgroup membership rather than reflecting a literal brand. It is nonetheless toxic, deeply constraining the life options for those in devalued outgroups. Crucially, people with mental disorders have been stigmatized throughout history and across nearly all cultures investigated. Indeed, the most stigmatized attributes a person can currently "hold" are substance abuse, men- 
tal disorder, or homelessness [Hinshaw, 2007]. Because nearly all relevant research utilizes traditional attitude scales, typically subject to social desirability bias, implicit measures may well reveal even greater levels of mental illness stigma. Discriminatory social policies (e.g., lack of parity with medical conditions in terms of reimbursement; laws that forbid running for office, serving on a jury, or maintaining child custody if one discloses a history of mental illness) provide compelling adjunctive evidence regarding the pervasive nature of stigmatization.

Composed of stereotypes, prejudicial attitudes, and discriminatory actions, stigma is a multifaceted construct. It is sufficiently universal that evolutionary roots, linked to fear of contagion and/or of being exploited, may well be present [Kurzban \& Leary, 2001]. As a result, reducing stigma and enhancing acceptance are complex matters, requiring multilevel efforts.

Two corollaries follow. First, although the process is not inevitable, members of stigmatized groups often internalize the pernicious attitudes of mainstream society. Along with structural barriers, such self-stigma is predictive of reduced help-seeking related to mental illness [Corrigan, Druss, \& Perlick, 2014]. Second, Goffman [1963] coined the term courtesy stigma, referring to societal tendencies to castigate and stigmatize anyone associated with a member of a stigmatized group. Such a pervasive "shadow" clearly applies, in the case of mental disorder, to family members. In fact, parenting practices were explicitly blamed as causing autism, schizophrenia, anxiety disorders, and most other forms of mental disorder during much of the 20th century [Hinshaw, 2017b]. As well, mental health professionals - scientists, clinicians, trainees, and the like - are also victims (and perhaps inadvertent perpetrators) of such courtesy stigma.

Finally, despite the growing tendencies for both scientists and the public at large to endorse neurobiological views of serious mental disorders, such underlying beliefs are no panacea in terms of stigma reduction [Pescosolido et al., 2010]. Contradicting core tenets of attribution theory - through which ascribing undesirable behavior to uncontrollable causes like genetic liability should reduce blame and stigma - metaanalyses reveal that holding such beliefs actually increases pessimism and desire for social distance [Kvaale, Haslam, \& Gottdiener, 2013]. In short, the reductionist ascription of mental illness to aberrant genes neither tells the whole truth about the multiple, interacting causes for mental health conditions nor automatically reduces stigma. Humanizing the individual experiencing mental disorder must be emphasized.

\section{Risk for Children of Parents with Mental Disorders, Particularly Mood Disorders}

Mood disorders run in families. Having a parent with episodes of depression doubles to triples an offspring's risk for developing depression - a condition with severe life consequences, currently ascending to unprecedented rates among the general population, especially women. Indeed, suicide (clearly linked to mood disorders like depression and bipolar disorder) is on the rise, comprising the second-leading cause of death for people under 30 and the leading cause for females aged 15-19, worldwide. 
Increasingly sophisticated behavior genetic research reveals substantial heritability figures for nearly all forms of mental disorder. At the same time, no single gene exists for any form of mental illness [Kendler, 2005]. Indeed, complex gene-gene and gene-environment interplay, including epigenesis, is hugely relevant for the expression of both typical and atypical development [Geschwind \& Flint, 2015].

In the case of mood disorders, major depression displays significant but moderate heritability, ranging from 30 to $40 \%$ [see Sullivan, Neale, \& Kendler, 2000]. Bipolar disorder is substantially more heritable, approximately double that for unipolar depression [Goodwin \& Jamison, 2007]. Indeed, with bipolar disorder (the co-occurrence of manias and depression in the same individual), disastrous consequences, particularly suicide risk, are legion.

The upshot is that a host of psychosocial mechanisms - co-occurring with or even independent of genetic transmission of mood disorders from parent to child are extremely relevant [see Goodman \& Gotlib, 1999; Goodman et al., 2011]. In particular, dysregulated emotion regulation and disturbed mood in parents are associated with lowered socioeconomic status, marital strife, inconsistency in parenting, general family dysfunction (including the modeling of either anger or despondency as coping responses), and - all too often - shame in talking with children about the mood-related issues that can too often affect supportive family interactions. In addition, many parents do not even comprehend that a mood disorder is part of the picture, attributable to lack of awareness, general societal stigma, and poor access to supportive care. Overall, societal stigma regarding disclosure of mental illness is undoubtedly related to the within-family shame and guilt that a depressed or bipolar parent often experiences when considering whether or how to disclose it to offspring. In my family, half a century ago, my father's diagnosis was completely inaccurate, and the mental health profession itself insisted that the most important issue staring our family in the face, every day, must be kept silent.

\section{Preventive Intervention}

What could my parents - who stayed together despite the odds, given Mom's utter lack of support during the worst of his episodes - have said when my sister and I were young? Clearly, saying nothing, as ordered professionally, precipitated internalization and parentification, as often occurs when children sense conflict but no explanation or emotional understanding is offered [see Hooper, DeCoster, White, \& Voltz, 2011]. In other words, whatever the transmitted genetic risk was enhanced by the shame and silence lingering inside our Midwestern home.

In a series of illuminating investigations, Beardslee and colleagues [Beardslee, 2002; Beardslee, Gladstone, Wright, \& Cooper, 2003; Beardslee, Wright, Gladstone, \& Forbes, 2007] have experimentally shown that interventions aimed at promoting open communication between parents and children, in families where a parent has a significant mood disorder, can enhance offspring understanding of the parental mood disorder and reduce, years later, their risk of internalization and depression. These are remarkable findings: beyond the heritable contributions to offspring risk for mood disorders in families where parental mood disorder is salient, enhancing cognitive and emotional understanding and promoting accurate and active family communication can reduce intergenerational risk [see also Saltzman, Pynoos, Lester, 
Payne, \& Beardslee, 2013]. In short, despite the undoubted genetic/biological contributions to the risk for transmission of mood disorders to the next generation, particularly for bipolar disorder, communication and humanization are extremely salient. That is, when children gain cognitive and emotional understanding of the nature of their parent's depression or disturbed mood and do not engage in self-blame for the family discord and crises that too often ensue, a virtuous cycle of support, understanding, and resilience can take place.

\section{Conclusion}

In the end, I hold to the belief that the ultimate answer lies in the process of $h u$ manization of those with mental disorders, along with their family members and associates. Cancer was rarely, if ever, placed in obituaries during the early part of the 20 th century, given the belief that it was a shameful disease brought on by weak personal will. In the present era fighting cancer is clearly a major social cause, largely via greater understanding of its origins as well as multiple testimonials from a wide variety of individuals and families.

Understanding the major contributions of developmental psychopathology with its emphasis on reciprocal, transactional pathways toward risk and resilience regarding the confluence of psychobiological and psychosocial roots of mood disorder should lead to major advances in research and practice. When the deeply human experiences of depression and bipolar disorder, and their consequences, can be communicated within families and across society, children can thrive and acceptance can replace stigma. At the same time, wider access to treatment, plus higher prioritization of mental health research and practice, should ensue.

\section{References}

Beardslee, W. (2002). Out of the darkened room: Protecting the children and strengthening the family when a parent is depressed (1st ed.). Boston: Little, Brown and Company.

Beardslee, W.R., Gladstone, T.R.G., \& O'Connor, E.E. (2011). Transmission and prevention of mood disorders among children of affectively ill parents: A review. Journal of the American Academy of Child and Adolescent Psychiatry, 50, 1098-1109. doi:10.1016/j.jaac.2011.07.020

Beardslee, W.R., Gladstone, T.R., Wright, E.J., \& Cooper, A.B. (2003). A family-based approach to the prevention of depressive symptoms in children at risk: Evidence of parental and child change. Pediatrics, 112, e119-e131. doi:10.1542/peds.112.2.e119

Beardslee, W.R., Wright, E.J., Gladstone, T.R.G., \& Forbes, P. (2007). Long-term effects from a randomized trial of two public health preventive interventions for parental depression. Journal of Family Psychology, 21, 703-713. doi:10.1037/0893-3200.21.4.703

Corrigan, P.W., Druss, B.G., \& Perlick, D.A. (2014). The impact of mental illness stigma on seeking and participating in mental health care. Psychological Science in the Public Interest, 15, 37-70. doi: $10.1177 / 1529100614531398$

Geschwind, D.H., \& Flint, J. (2015). Genetics and genomics of psychiatric disease. Science, 349, 1489-1494. doi:10.1126/science.aaa8954

Goffman, E. (1963). Stigma: Notes on the management of spoiled identity. Englewood Cliffs, NJ: PrenticeHall.

Goodman, S.H., \& Gotlib, I. (1999). Risk for psychopathology in the children of depressed mothers: A developmental model for understanding mechanisms of transmission. Psychological Review, 106, 458-490. doi:10.1037/0033-295X.106.3.458 
Goodman, S.H., Rouse, M.H., Connell, A.M., Broth, M.R., Hall, C.M., \& Heyward, D. (2011). Maternal depression and child psychopathology: A meta-analytic review. Clinical Child and Family Psychology Review, 14, 1-27. doi:10.1007/s10567-010-0080-1

Goodwin, F.K., Jamison, K.R. (2007). Manic-depressive illness: Bipolar disorders and recurrent depression (2nd ed.). New York, NY: Oxford University Press.

Hinshaw, S.P. (2007). The mark of shame: Stigma of mental illness and an agenda for change. New York, NY: Oxford University Press.

Hinshaw, S.P. (2017a). Another kind of madness: A journey through the stigma and hope of mental illness. New York, NY: St. Martin's Press.

Hinshaw, S.P. (2017b). Developmental psychopathology as a scientific discipline: A twenty-first century perspective. In T.P. Beauchaine \& S.P. Hinshaw (Eds.), Child and Adolescent Psychopathology (3rd ed., pp. 3-32). Hoboken, NJ: Wiley.

Hooper, L.M., DeCoster, J., White, N., \& Voltz, M.L. (2011). Characterizing the magnitude of the relation between parentification and psychopathology: A meta-analysis. Journal of Clinical Psychology, 67, 1028-1043. doi: $10.1002 /$ jclp. 20807

Kendler, K.S. (2005). “A gene for...”: The nature of gene action in psychiatric disorders. American Journal of Psychiatry, 162, 1243-1252. doi:10.1176/appi.ajp.162.7.1243

Kurzban, R., \& Leary, M.R. (2001). Evolutionary origins of stigmatization: The functions of social exclusion. Psychological Bulletin, 127, 187-208. doi:10.1037/0033-2909.127.2.187

Kvaale, E.P., Haslam, N., \& Gottdiener, W.H. (2013). The "side effects" of medicalization: A meta-analytic review of how biogenetic explanations affect stigma. Clinical Psychology Review, 33, 782-794. doi: 10.1016/j.cpr.2013.06.002

Pescosolido, B.A., Martin, J.K., Long, J.S., Medina, T.R., Phelan, J.C., \& Link, B.G. (2010). “A disease like any other"? A decade of change in public reactions to schizophrenia, depression, and alcohol dependence. American Journal of Psychiatry, 167, 1321-1330. doi:10.1176/appi.ajp.2010.09121743

Saltzman, W.R., Pynoos, R.S., Lester, P., Layne, C.M., \& Beardslee, W.R. (2013). Enhancing family resilience through family narrative co-construction. Clinical Child and Family Psychology Review, 16, 294-310. doi:10.1007/s10567-013-0142-2

Sullivan, P.F., Neale, M.C., \& Kendler, K.S. (2000). Genetic epidemiology of major depression: Review and meta-analysis. American Journal of Psychiatry, 157, 1552-1562. doi:10.1176/appi.ajp.157.10.1552 